Conclusion 



\title{
You Can't Sell Free, and Other OER Problems
}

\author{
Robert Biswas-Diener \\ NOBA Project, robert@nobaproject.com
}

When I took the senior editor position at Noba-a service providing open materials for students and instructors of psychology (see Chapter 16, this volume)-I loved the idea of transforming education in general, and the field of psychology specifically. I assumed that a free, high quality textbook would be seen as more attractive than a costly counterpart and I worried that our small staff would not be able to keep up with the demand of instructors clamoring for our resources. Instead, I was greeted with alternating indifference and disdain. The indifference was largely the product of inertia. Instructors weren't looking to change course materials when their current materials were working just fine, at no cost to themselves. Understandably, switching books represented a huge amount of work for instructors including creating new lecture materials and tests. The disdain came from a deep suspicion of Noba and open materials in general. I shouted-metaphorically-until my voice gave out about how Noba materials didn't cost a cent. 'It sounds too good to be true,' I heard time and again. If I used the word 'free' in open posts to professional societies, in e-mails or at conferences, the reactions were even harsher. I was asked to quit spamming list serves and some groups were even reluctant to share news that Noba was handing out monetary grants to students. It was a frustrating time.

My team and I quickly realized that there were hurdles to overcome if we wanted to be effective in our educational mission. These hurdles were not necessarily related to the quality of our materials, to our brand reputation, or to

How to cite this book chapter:

Biswas-Diener, R. 2017. You Can't Sell Free, and Other OER Problems. In: Jhangiani, R S and Biswas-Diener, R. (eds.) Open: The Philosophy and Practices that are Revolutionizing Education and Science. Pp. 257-265. London: Ubiquity Press. DOI: https://doi.org/10.5334/bbc.u. License: CC-BY 4.0 
our lack of professional connections within psychology. Instead, the greatest obstacles to sharing our resources were related to fundamental problems concerning open philosophy itself. In this chapter I would like to address three of these problems: 1) problems with the basic open narrative, 2) common misperceptions concerning open resources, and 3) problems concerning the best advocates for open. It should be noted that I do not think that I have arrived at the final answers or the most insightful conclusions regarding these issues. Instead, it is my hope that this chapter will plant the seeds of discussion and reflection that might subtly influence the ongoing battle for open.

\section{Fixing the Narrative}

In his book, The Battle for Open, Martin Weller (2014) presents a cogent argument that it is Silicon Valley-venture capitalists and technology companiesthat have offered the most compelling contemporary narrative concerning education. In Weller's estimation this narrative can be summed up in the single, strong statement 'education is broken.' It is a powerful rallying cry because it is suggestive of so many verbs: disruption and revolution. Conspicuously absent from the discussion of both disruption and revolution is widespread reflection about the degree to which either actually will yield superior outcomes or tangible improvements. Even more damning, perhaps, is Weller's argument-one I find personally persuasive-that the 'education is broken' narrative is inaccurate. By way of counterpoint, consider the following:

- More people are being educated than at any time at history, and this includes secondary and tertiary education.

- There is greater gender equality in education than at any time in history. ${ }^{1}$

- Educators at all levels continue to advance their pedagogic methods and improve best practices.

Unfortunately, 'No, it's not!' falls short of being an effective response to the Silicon Valley story. This is, in part, because there are a number of legitimate problems with education. In the United States, for instance, there are a number of difficulties with funding public education and rising costs associated with higher education. In other countries, such as Australia, there has recently been a push toward increased testing, and many educators see this as a potential pedagogic mis-step. ${ }^{2}$

It would be wonderful if advocates of open education in general, and open practices in psychology education specifically, had an effective narrative of our own. For all its virtues 'open' has long been plagued with problems. The idea that products and services might be offered free of charge, for instance, is often associated with inferior quality or an outright scam. Also problematic are the very traditions of the academy itself. Many university instructors prize 
their own expertise above all else and, historically, there has been no greater vessel for this showcase of knowledge than in publication. To suggest that publications will not only be shared freely, but might actually be modified, is offensive to that tradition. Similarly, suggesting to many academics that their teaching methods and resources might be openly distributed and modified can be disquieting, suggesting as it does the potential obsolescence of some instructors.

I, myself, had a difficult time transitioning from a more conventional educational mindset to my current understanding of the benefits of open philosophy. For instance, when I first learned about Creative Commons licensure I reacted in a way that I have since learned is common: I was horrified. The idea that someone could re-write or re-sell my writing was anathema to my academic sensibilities. My attitude changed when I began to consider 'impact', broadly defined, as an important outcome for my writing. Based on the traditional academic publishing model a few of my articles have made an impact: I have 13 publications with more than 100 citations each. It is hard to estimate exactly what that means but it is fair to say that a few of my ideas have been read by my peers and, perhaps, even influenced their thinking in some small way. Then again, a cover story I wrote for Psychology Today (2013) magazine was openly shared 18 thousand times on social media. An article I wrote on self-determination in the Montessori school pedagogy was published in an open journal and was downloaded more than 8,000 times. In one study conducted by the Research Information Network (2014) articles appearing in the journal Nature Communications were read twice as often as their non-open counterparts six months after publication. Similarly, the open publications received about one and a half times the number of citations than did their closed counterparts. If one measure of success is the amount a publication is actually read then removing barriers to reading it seems sensible to me.

To the extent that there are other psychologists who might be initially skeptical of open approaches-and they are legion-I argue here that open needs a compelling narrative of its own. Open, itself, is often treated like an adjectiveas in, 'this open textbook is free for students' - rather than as a verb, as in 'if we open this course it will be available to people around the world.' In the first instance the word open is equated with being free as opposed to its more accurate meaning in which it includes greater potential for collaboration, innovation, and contextualization. So, what is it that open is doing for education? I believe that open is helping to spread education and here-in my opinion-is a potentially productive narrative: 'education is spreading.' Due to the intertwined factors of digital technology and open philosophy education is creeping out of its traditional repositories. The most progressive institutions are keeping pace by following suit: they are offering on-line and distance learning, adult learning and certificate programs, MOOCs, micro-credentials, and access to foreign campuses. Treating openness like an action feels dynamic and is a better banner than open as an adjective. 
I am attracted to this particular narrative for several reasons. First, the notion that education is spreading is a far more positive message than education being broken. I do not mean to suggest here that we whitewash legitimate problems associated with education in general, or psychology in particular. Rather, I think the idea of the spread of education speaks to the unspoken mission of people attracted to psychology: we believe that our field is so fundamentally interesting, so worthwhile in its exploration of the human mind and in the creation of interventions, that we wish that it was available to everyone. While many psychologists feel overwhelmed at the prospect that their field may be broken they might be energized to learn that it is spreading.

Another reason the 'openness leads to spreading' narrative is so compelling is that it is suggestive of sharing. Keltner (2009) and others offer evidence that altruism is a fundamental aspect of human nature. By appealing to the better angels of this nature open education has a 'we're all in this together' leaning. In a field plagued by academic cat fights, big egos, critical peer reviews, and departmental politicking, the promise of open psychology offers a salve. It overtly suggests that we can all better achieve the most non-controversial missions of our discipline-high quality research, effective teaching, effective intervention-if we share our data, our methodology, our resources, and our experiences.

I would like to linger on the issue of sharing for a moment. In some people's minds the notion of sharing is synonymous with 'giving away'. In the same way that sharing a cup of sugar with a neighbor means that you have one fewer cups of sugar. The sharing implied by open educational philosophy is similar to the knowledge we share in the classroom. When we lecture students we do not find our own reserves of knowledge somehow depleted. At its best open practices allow people to retain control of their content or methods or data even as they allow other people to use them as well.

Finally, the spread of education may be appealing because of its suggestionsubtle or great-that this process is inevitable. Ask any editor at a major academic publisher and they will likely agree with this sentiment. They understand that the landscape of journals has changed radically in the last decade. These days, authors share PDFs of their work on private web sites. In fact, this common practice often occurs in violation of copyright law. Even so, many academics see such sharing as part of a broader mission to make an impact that outweighs the potential legal risks. These days, fee-based journals also compete against open journals and even against non-traditional outlets like blogs and news stories. There are scandals involving replication and p-hacking. In my experience, these editors have read the tea leaves and are scrambling to adjust their approach to the market. They are finding ways to ride these currents instead of fighting against them. The most successful universities, like the most successful publishing companies, will be those that accept the inevitable and find a way to work within the new open landscape. 
Despite all this positivity it is likely that the education is spreading narrative will spike the blood pressure of many worried instructors. In an age where information is flowing freely and the collected publications of research psychologists are available on the internet many people worry about the role that academics will play in this new landscape. There are, I believe, three primary roles for psychologists in the future. In the information age there is more demand than ever for researchers to create new knowledge and act as 'upstream' agents in the knowledge pipeline. We are seeing early versions of this as increasing numbers of researchers blog about their work and that of their colleagues. In addition, some academics will serve as interventionists - therapists and consultants-helping to bridge concepts an applications. Finally, the nature of psychology instruction will shift. Academics will find less call to be the 'sage on the stage' offering content-packed lectures to large halls of note scribbling students. In their new incarnation, instructors will act as a 'guide on the side' in which they facilitate learning by leading discussions, activities, and otherwise curating knowledge. There will still be demand for teachers but teachers will not solely be 'tellers.'

\section{Fixing the Common Misperceptions}

In the few years I have spent as an advocate of open educational resources I have heard more than a few skeptical remarks. These remarks have come to me first-hand through e-mails and conversations at conferences. And they have come to me back channel as I have heard from members of professional bodies and department heads who confess that open education resources are a potential threat to individual and departmental revenue. Roughly, I divide skepticism into two categories: challenges to quality and challenges to control of content. Challenges to quality or common among people who are considering adopting materials such as open textbooks. Challenges to control of content are common to people who are considering creating open materials such as lectures or chapters. In both cases I would like to confess that I am sympathetic. I believe my colleagues are-fundamentally-no different than me. We all want the best for our students. We all want to reduce the stress of our respective workloads. We all want to earn an adequate income.

\section{Quality}

Many times I have heard skeptics of OER apply the adage 'you get what you pay for' with reference to free resources. There is an assumption that the processes that lead to high priced products are the same as those that lead to high quality products. It is a fallacy, however, to jump to the conclusion that free or inexpensively produced products, by contrast are of lesser quality. Many 
OERs, including Noba, have sophisticated adaptive learning technologies and expert created instructor's manuals and other materials that hold up well in side-by-side comparisons. In fact, Noba materials are expensive to produce and our costs include editing, software, expert consultation and other expenses. 'Free to students' should not be equated with 'free to produce.' I believe that the concerns over quality are, in large part, a historical spillover from the early days of OER in which products may actually have been of lower quality. What needs to happen-and increasingly is - is that instructors considering using OERs need a formal rubric for evaluating their quality.

\section{Control over content}

In 2007 I was proud to publish my first book. It sold as well as niche academic titles do. Then, in 2009 I received an e-mail from a psychologist in Iran. He told me that he had taken the liberty of translating my work into Farsi and was releasing it in his country. Since Iranians are not subject to international copyright laws, he continued, he did not need to ask my permission. He did, however, want to know if I would be willing to write an introduction to the Iranian volume! It was the first time I experienced losing control of my own intellectual property. I worried about the quality of his translation. I worried about my own potential loss of revenue. I worried that he might somehow misrepresent my work and thereby impugn my reputation. Then, after consideration, I came to terms with those worries as I realized than any loss of income was almost certainly negligible and that this man's 'piracy' had likely expanded my impact by spreading my ideas to a corner of the world they might not otherwise reach.

Most people's concerns regarding losing control of their intellectual property or reputation are understandable in spirit but do not play out in fact. A large part of the openness in OER is related to removing obstacles to sharing information. If a researcher were to publish her paper on college student stress in an open format, for example, she would be able to share it widely. It would be accessible to students, lay people, reporters and colleagues who might not otherwise have subscriptions to a traditional journal. When I look at my own academic publication record, I have recently shifted to submitting more often to open journals. I am still attracted occasionally to the siren song of top tier journals and the prestige they bring but I have been personally swayed by the obvious impact of my open publications. This stickier concern is that someone might appropriate your work, impugn your reputation, or attenuate the quality of your writing. Unless you are a best-selling author or major public figure I would encourage you to take a deep breath on this point. The single most likely thing to happen if you were to openly license your work is that a wellintentioned colleague would add some research references or make cosmetic edits to enhance its readability. 
Ultimately, I believe that the solution to the problem of OER's less than stellar reputation is going to be found in peer testimonials. There is increasing research attention being paid to these resources, and to the extent that the results of these studies act as an endorsement of OER, it will help bolster people's confidence in them. The more powerful route to persuasion, I argue, will be when a colleague down the hall gives OER their professional seal of approval. Whether it is a peer who has created open lectures or one who has adopted an open textbook the truth is their words hold more water than do mine. For this reason I believe that all of us who use OERs have an obligation to speak publicly about our experiences with them.

\section{Who is the best advocate for OER?}

It may seem strange to ask who is best positioned to advocate for OER. Given the academic benefits, the social justice consequences, and the economic solutions that OER represents it is tempting to suggest that everyone ought to speak out. Truth be told, there are better and worse sales people. Historically, people in the OER vanguard are a select group: we are not the 'establishment.' We are not the most famous clinicians or the most highly cited researchers. We tend not to be associated with the most prestigious universities in the world. In essence, we are radicals and experimenters. In this respect we bear some small resemblance to social activists at the beginning of many other movements. Like them, it can be easy to dismiss our collective racket as the chanting of a disgruntled few until we reach a critical mass.

I argue here that we will reach a critical tipping point-one in which OER shifts from being a fringe experiment to the being standard operating procedure-when the circle of advocates expands beyond the vanguard. When the advocate group includes students, famous psychologists, and administrators OER will have arrived. I mention students especially because they are, by definition, the ultimate reason for OERs. The lack of student participation in the discussions about the creation, adoption and use of OERs is perplexing. Largely, I think their absence reflects a tradition in which education is done to students rather than with them. I would love to see more students demanding open materials as well as having a hand in their creation. Similarly, I would love to see the most established psychologists - those with the highest citation counts and best reputations-endorse OERs. Although it might sound crass to compare our intellectual luminaries to the types of celebrity endorsements we see on television I will admit that I would be swayed in many academic matters by testimonials from my most admired colleagues.

And here-with the example of a changing publishing industry fresh in mind - we arrive at the final thorny question regarding OER advocacy: regardless of who endorses OER the decision to use them is sometimes out of the hands of individual instructors. In some institutions it is the department as 
a whole that makes such decisions. In addition, state and professional mandates may also be factors that affect the decision to adopt OERs. Among the uphill battles for OER is the fact that individual instructors who are willing to experiment with pedagogy might be hamstrung by departmental policy. Some departments have cleverly dealt with individual differences in their faculty by allowing individual instructors to make their own decisions regarding OERs such as open textbooks. Other departments have assigned a traditional textbook common to all courses but have simultaneously allowed an optional open text alternative. There is, unfortunately, no standard way forward. Instead, the issue of how open education is spreading will be sorted by each unique context in which it arises.

\section{Conclusion}

I would like to conclude with something other than a standard summary of the key points you have just read. You are intelligent and I trust that you understood this chapter well and that you will consider its points with the same seriousness that you reflect on all other points of your instruction. Instead, I would like to close on an exciting note. Open education is transforming old institutions in eye-popping ways. Because I work with Noba I will use the single example of textbooks. Traditionally, textbooks have been books. That is, they have been single bound hard-copy volumes that act as a survey of the most important information in a particular field. With the advent of open education textbooks were more likely to be digitized and more likely to be free of charge. An improvement to be certain but still a traditional view of a book.

Currently, we are able to experiment with new understandings of textbooks that allow for improved teaching. Noba, by way of specific example, allows every instructor to pick and choose the content she wants to include and arrange it in any order she chooses. She can make it available digitally or in hard copy. The advantages of digital technology also allow us to enhance the text with mouse-over technology that allows readers to see pop-ups of full references or key vocabulary terms. We now have the capacity for students to take adaptive learning quizzes inside each chapter as they read it. Most interestingly still, it is now possible for instructors to design a textbook with core content and for each individual student to customize this common core with supplemental chapters that are unique to his or her own interest. For the first time in history each student in class could have a truly individualized textbook written by experts but which they, themselves, customized.

This is just a single example of the ways that openness can lead to new developments in pedagogy. It is time that we quite asking about the quality of open education resources. Instead, we should be asking, 'Now that education is spreading, what are we going to do with it?' 


\section{Notes}

1 UNESCO Institute for Statistics, 2013.

2 Bowden, 2014; Cashen et al., 2012.

\section{References}

Bowden, T. (2014). NAPLAN study finds testing causes students anxiety, program not achieving original goals. Retrieved from: http://www.abc.net.au/ news/2014-05-19/naplan-study-finds-school-testing-program-not-achievinggoals/5463004

Cashen, J., Hornsby, D., Hyde, M., Latham, G., Semple, C., \& Wilson, L. (2012). Say no to NAPLAN. Retrieved from: http://sydney.edu.au/education social_work/news_events/resources/No_NAPLAN.pdf

Kashdan, T. B., \& Biswas-Diener, R. (2013). What happy people do differently. Psychology Today, 46(4), 50-59, Retrieved from: https://www.psychology today.com/articles/201306/what-happy-people-do-differently

Keltner, D. (2009). Born to be good: The Science of a Meaningful Life. New York: W.W. Norton \& Company.

Research Information Network. (2014). Nature communications: Citation analysis. Retrieved from: http://www.nature.com/press_releases/ncommsreport2014.pdf

UNESCO Institute for Statistics. (2013). Adult literacy rate, both sexes (\% ages 15 and older). Retrieved from: http://hdr.undp.org/en/content/adult-literacyrate-both-sexes-ages-15-and-older

Weller, M. (2014). Battle for Open: How openness won and why it doesn't feel like victory. London: Ubiquity Press. DOI: http://dx.doi.org/10.5334/bam 
